\title{
Spirituality in the workplace and spiritual intelligence- A new paradigm for a more effective workforce in an organization
}

\author{
Amrendra Pandey
}

\section{Introduction:}

Despite all our gains in technology, product innovation and world markets, most people are not thriving in the organizations they work for. They are neither fulfilled nor excited .If we walk into any Organization these days we will find it full of fear, anger, resistance to change, and employees who are there just for the paycheck. The best employees are usually looking to go elsewhere, and the employees who are not so marketable are trying to stay under the radar and just hang on for dear life. They are not clear about where the organization is headed or what its highest priorities are. They are bogged down and distracted. Most of them don't feel they can change much.

Today we find ourselves asking, what is the essential ingredient necessary to ensure the short and long-term success of an organization? What is the formula for high productivity and high performance? What is the way to create a sustainable organization?

\section{The problem and the questions:}

We sense a dangerous disease infecting our modern culture and eroding hope: an increasingly prevalent view that greatness owes more to circumstance, even luck than to action and discipline-that what happens to us matters more than what we do. In games of chance, like a lottery or roulette, this view seems plausible. But taken as an entire philosophy applied more broadly to human endeavor, it's a deeply debilitating life perspective, one that we can't imagine wanting to teach young people. Do we really believe that our actions count for little, that those who create something great are merely lucky, that our circumstances imprison us? Do we want to build a society and culture that encourages us to believe that we aren't responsible for our choices and accountable for our performance?

Present business pressures for more successful operation are creating new workplace demands. They are forcing the organizations to acknowledge that a radically different way of operating is going to be required for business survival and competitiveness. Following are some of the findings of an Execution Quotient Test (Xq Test), a questionnaire which measures the "execution gap"-the gap between setting a goal and actually achieving it. After surveying around 2.5 million people on the effectiveness of their Managers, and in association with Harris Interactive (The Originators of the Harris Poll), Franklin Covey has developed a method for measuring execution capability. They polled 23000 U.S. residents employed full time within key industries and in key functional areas.

Some of their findings are:

1. Only $37 \%$ said they have a clear understanding of what their organization is trying to achieve and why

2. Only 1 in 5 was enthusiastic about their team's and Organization's goals.

3. Only half were satisfied with the work they have accomplished at the end of the week.

4. Only 1 in 5 workers said they have a clear "line of sight" between the tasks and their team's and Organizations goals.

5. Only $15 \%$ felt that their Organization fully enables them to execute key goals.

6 . Only $15 \%$ felt they worked in a high-trust environment.

7. Only $17 \%$ felt their Organization fosters open communication that is respectful of differing opinions and that results in new and better ideas.

8. Only $10 \%$ felt that their Organization holds people responsible for results.

9. Only $20 \%$ fully trusted the Organization they worked for.

10. Only $13 \%$ have high trust, highly co-operative working relationships with other groups or departments.

Where have we gone wrong? Majority of the workforce in our Organizations possess far more talent, intelligence, capability and creativity than their present jobs require or even allow. About the same percentage acknowledge that they are under immense pressure to produce more for less.

\section{PURPOSE:}

The purpose of this project is to find out the reasons and present compelling argument for why spirituality may be that ingredient, when consciously acknowledged and channeled into an organization's day to day operation. 
In addition to finding a solution to the above problems, we will also try to find answers to the following questions:

1. How does an Organization continually adapt to its changing business environment?

2. What is the driving force that makes people creative and innovative in the Workplace?

3. How can the personal goals and objectives of the people be brought in alignment with the objectives and targets of the Organization?

4. How to make the employees more responsible and accountable for their work in proportion to their competencies?

Spirituality in the workplace - a new management paradigm for High Performance Organizations.

A Brief History: In the late 1970s and throughout the 1990s, an expansion of management theories included focus not just on the workers as physical beings, or as emotional beings but also as thinking beings. With the advent of Quality circles and similar approaches came the recognition that workers did not check their minds at the door when they came to work, but in fact, they were actually the experts at their jobs and probably knew more about how to make things better than the engineers.

As our concept of what it means to be human is expanding, so too are our management theories expanding .With recent research in quantum physics and holistic medicine, people are coming to accept that humans are also spiritual beings, that we are the sum of body, mind emotion and spirit.

As crass as this may sound, spirituality is the new competitive edge. Most organizations are physically efficient, and they attend to the emotional and social needs of employees to some degree. They have learned how to involve employees in decision making and to tap their intellectual abilities. But how many of them have learned to tap into the human spirit?

When I talk about Spirituality and Human spirit, I mean two things:

First, I mean a connection to something greater than ourselves, whatever one might call it; second, I mean a sense of meaning and purpose that guides our lives.

Organizations which have long been viewed as rational systems are considering making room for the spiritual dimension, a dimension which has less to do with rules and order and more with meaning, purpose and a sense of community.

In his book "The Living Organization-spirituality in the work place " Prof. William A. Guillory says that the key characteristic of a Living Organization is its ability to continually transform in response to the changing business environment. An organization's drive to continually change is similar to the adaptive nature of biological organisms that evolve over time. And, as is true for biological organisms, those organizations that do not learn to adapt, usually become extinct. For example, in the mid-1980s it became clear to many business leaders that operating an organization according to the previously acceptable "command and control" style was no longer competitive. This way of operating had simply become too slow, inefficient, and resistant to change to keep up with the complexity of accelerated change experienced by most companies. In response to that realization, proactive organizations began the significant integration of high employee involvement, teamwork, and empowerment into their management practices.

A high performing organization is one that continually adapts to its changing business environment. Adaptation occurs as a result of individual and organizational transformation. Transformation is an irreversible change in the mind-set of an organization's leadership and employees. It sets the stage for a continous improvement and often a new way of operating. Such change commonly results in an organization redefining its vision, strategy, and performance expectations.

Five reasons for Corporate World's growing interest in spirituality at work are as follows:

1. The downsizing, reengineering and layoffs of the past decade, which have turned the Workplace into an environment where employees are demoralized.

2. The fact that the workplace is increasingly seen as a primary source of community for many people because of the decline of neighbourhoods churches, civic groups, and extended families as principal places for feeling connected.

3. The increased access to and enhanced curiosity about Eastern philosophies. Philosophies such as Zen Buddhism, Taoism and Sufism encourage meditation and emphasize values such as group loyalty and finding one's spiritual centre in every activity.

4. The fact that aging baby boomers are moving ever close to life's greatest uncertainty -death and thereby develop a growing interest in contemplating life's meaning.

5. The fact that there is increasing pressure of global competition which has led organizational leaders to realize that employee creativity needs nurturing.

Today we must accept the fact that we have not created work environments where people are given the authority to be responsible and accountable for their work in proportion to their competencies. When provided this opportunity, most individuals respond by tapping into an inherent inner source that drives 
their performance. Therefore, the most powerful source of motivation comes from within. In fact this is the only sustainable source of motivation.

Spirituality in the workplace is about people who perceive themselves as spirited beings, whose spirits desire and need to be energized through work. It is about experiencing real purpose and meaning at work beyond paychecks and performance reviews. According to Harrington (2004) Spirituality is about people sharing and experiencing some common attachment, attraction and togetherness with each other within their work unit and the Organization as a whole. According to Mitroff and Denton(1999) Workplace spirituality involves the effort to find one's ultimate purpose in life, to develop a strong connection to co-workers and other people associated with work and to have consistency or alignment between one's Core beliefs and values of their Organization.

Spirituality and ethical behaviour in the workplace:

The link between religion and work is not new. For centuries, people have strived to interpret their work through religious lenses. Recently, however, a significant paradigm shift has occurred. The current view is that spirituality, as opposed to religion, is a better construct for under-standing the relationship between the individual and modern pluralistic workplaces. This current perspective, sourced in various socio-cultural factors, views spirituality as positively influencing numerous organizational outcomes. Also implicit within this discourse is the notion that allowing and encouraging spirituality in the workplace leads to improved ethical behavior at a personal level and an enhanced ethical climate/culture at an organizational level.

Spirituality acts as a regulative ideal. This 'ideal' generates an embedded network of specific moral values that represents an 'internalized disposition' to act and be motivated in particular ways which address a spiritual individual's conception of what makes for excellence, in terms of their roles and responsibilities. The regulative ideal will provide a standard that informs judgement and helps to govern moral choices made in the context of daily working practice. It will be a reference point that will help to regulate both motivation and conduct so that a spiritual individual tends to conform to their internalized conception of good or excellent spirituality. To put this differently, motivations, decisions and actions that harmonize with a person's regulative ideal are appropriate and practiced, while those that clash with it are rejected. Through repeated acts, these values become "inculcated specific habits of the heart [i.e. virtues]" (Spohn,1997, p. 3) which, in turn, contribute to the further development of one's spiritual character. This person, because they have developed certain virtues, will act ethically, that is, do the right thing at work and elsewhere.

\section{Other advantages of applying Spirit at work mindset}

The authors have also referred to the potential benefits to managers, employees, and society of a spiritually oriented workplace. A team of researchers presented four interesting advantages in their review of employees who maintain the spiritual mindset:

1. The stronger the spiritual factor of personality, the more tolerant the person is of work failure, and the less susceptible the person is to stress.

2. The stronger the spiritual factor of personality, the more the person favors the democratic style of leadership, the more trusting the person is, and the higher the person's tolerance is of human diversity.

3. The stronger the spiritual factor of personality, the more the person exhibits altruistic behavior and citizenship.

4. The stronger the spiritual factor of personality, the more the person's commitment to the organization and work group increases.

Definition of Spirituality in the workplace:

The emerging paradigm called "spirituality in the workplace " is expressed in many ways. Some authors say that a fundamental tension between rational goals and spiritual fulfillment now haunts workplaces around the world, and that survey after management survey affirms that a majority want to find meaning in their work. Other authors hold that something has been stirring in worker's souls for quite some time now-a longing for deeper meaning, deeper connection, greater simplicity, a connection to something higher.

Bruce Jentner, president of Jentner Financial Group in Bath, Ohio recognizes this trend:" I have a deep conviction that everybody has a need for something bigger in life than just making money and going to work."'Other authors view this topic even more broadly, describing work as a spiritual journey for many of us, although we talk about it in many ways.

Chris Sangster, writes "Spirituality can be seen basically as displaying and applying a heightened level of awareness towards others in a selfless way. The benefits of such an approach are clearly greater staff loyalty and retention leading to increased productivity and creativity."Sangster reemphasized an often-presented clarification in context of spirituality in the workplace when he placed religion out of the scope, stressing that "It 
is possible to lead a 'spiritual' way of life without following any particular religious path."In Sangster's opinion spiritual workers are those who

think co-operatively and/or altruistically; have a balanced objective view of the world; listen as much as (or more than) they speak; apply three dimensional bigger picture thinking; believe in some higher driving force and purpose beyond humankind; find the time to think things through objectively; think laterally in order to promote realistic solutions; encourage and empower others selflessly; work openmindedly with a wide range of people;consistently display integrity and trust ,and; expect the best from people without being a "soft touch".

The following definition of spirituality in the workplace has been formulated by authors Dr Joan Marques, Dr Satinder Dhiman and Dr.Richard King

"Spirituality in the workplace is an experience of interconnectedness among those involved in a work process, initiated by authenticity, reciprocity and personal goodwill; engendered by a deep sense of meaning that is inherent in the organization's work; and resulting in greater motivation and organizational excellence."

\section{Spiritual Intelligence:}

At the core, there is one simple reason why so many people remain unsatisfied in their work and why most organizations fail to draw out the greatest talent, ingenuity and creativity of their people and never become truly great, enduring organizations .It stems from an incomplete paradigm or flawed paradigm of who we are-our fundamental view of human nature.

The fundamental reality is, human beings are not things, needing to be controlled .They are four dimensional-body, mind, heart and spirit .If we study all philosophy and religion ,both Western and Eastern, from the beginning of recorded history, we will find the same four dimensions: the physical/economic ,the mental, the social/emotional and the spiritual. Different words are often used, but they reflect the same four universal dimensions of life. They also represent the four basic needs and motivations of all people: to live (survival), to love (relationships), to learn (growth and development) and to leave a legacy (meaning and contribution).

In 'Built to last', a book based on intensive research on why some companies continue to thrive even in adverse conditions while others cannot, Jim Collins writes "We believe the real difference between success and failure in a corporation can very often be traced to the question of how well the organization brings out the great energies and talents of its people. What does it do to help these people find common cause with each other? ... And how can it sustain this common cause and sense of direction through the many changes which take place from one generation to another? ...I think the answer lies in the power of what we call beliefs and the appeal these beliefs have for its people.... I firmly believe that any organization, in order to survive and achieve success, must have a sound set of beliefs on which it premises all its policies and actions. Next, I believe that the most important single factor in corporate success is faithful adherence to those beliefs.... Beliefs must always come before policies, practices, and goals. The latter must always be altered if they are seen to violate fundamental beliefs. 

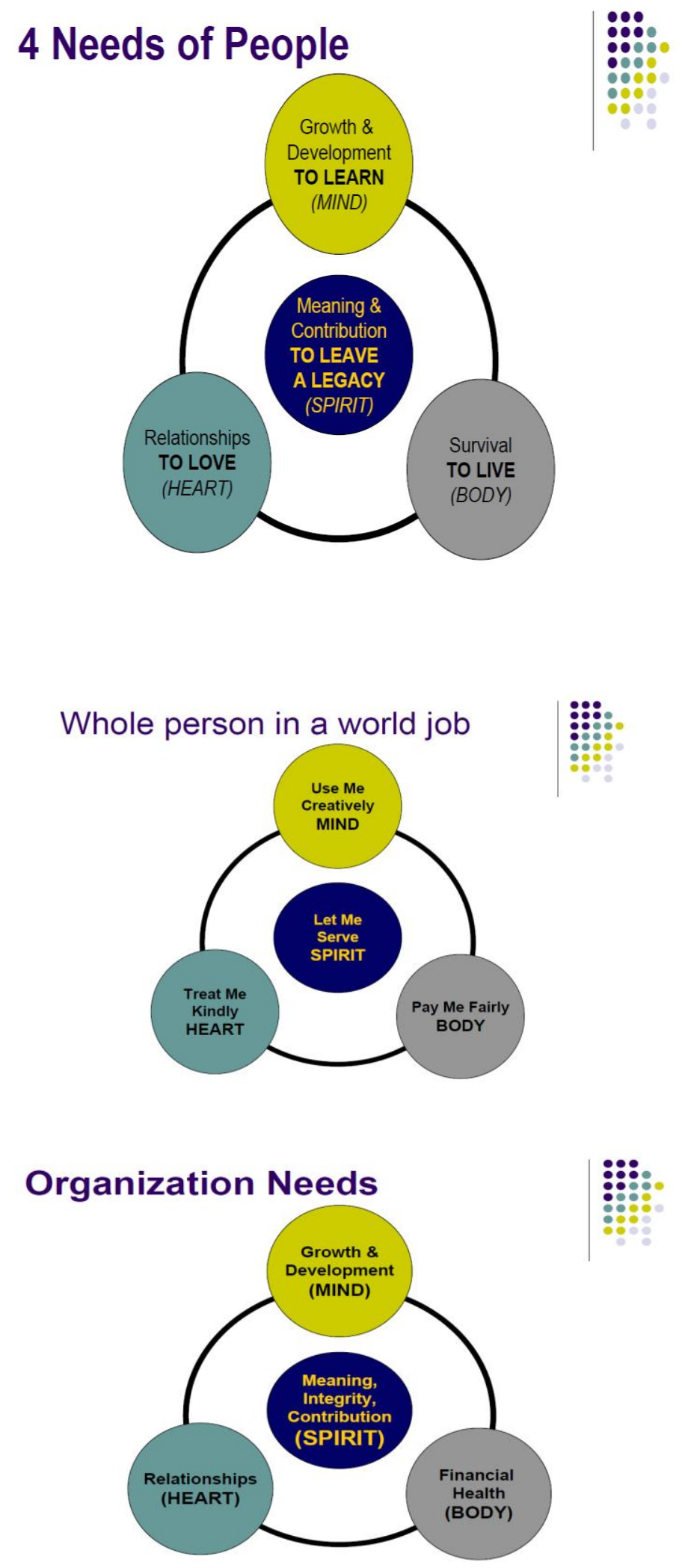

Spiritual intelligence can be defined as the backbone of human consciousness, responsible for character-building and meaning making. Developing spiritual intelligence is more of an experiential rather than a theoretical process. Thus, it is difficult to accurately define spiritual intelligence in literal terms without retreating into 
metaphors and symbols. The language of spiritual intelligence is the language of the heart .Everyone understands it, but in order to speak about it linguistically, we need to better understand the language of intuition, imagination and creativity. This is especially significant for multi-cultural teams where people come from all walks of life and all corners of religious backgrounds.

In a practical sense, the enhanced ability of linguistically communicating what is beyond words is a remarkable tool for multi-cultural leadership and teamwork .It is important to stress here that I am not referring to a mere exchange of feelings but rather the unity of being that comes from a deep sense of knowing.

David Hawkins suggested that spiritual intelligence serves as a "cross-paradigmatic dictionary". Integrating the interface of spirituality and science, spiritual intelligence can work with the empirical methods in order to explain the phenomenon of invisible. This is specifically useful in dealing with agnostics, skeptics or even atheists who need practical perspectives in learning contemplative disciplines (Hawkins, 2006).

A core aspect of healthy spiritual intelligence is awareness of the difference between the inner and outer worlds. Being able to interpret the events and experiences of life with a healthy balance of mind and spirit is a good indicator of having strong levels of emotional, social and spiritual competency. There are many people who struggle with being at the mercy of the relentless chatter of their inner critic. They are unaware of the spiritual inner world of their being which supports and protects them. These people often do not have consciously aware, loving and caring people in their lives. The result may be that they have a complete lack of connection to their own inner wise counsel, or human spirit.

Ken Wilber described spiritual intelligence as "literacy in the practice of transformation" and he further pointed out that spiritual intelligence is fast becoming a leadership imperative (Wilber, 2000b, p95).

Robert Emmons defined spiritual intelligence as a framework for identifying and organizing the skills and competencies needed for the adaptive use of spirituality (Emmons, 1999, p163).

\section{Conclusion:}

In a complex world filled with some difficult life conditions, who is best prepared to lead? Whether we are talking about an organization, a country or just inspiring the people around us, it is the leader at the highest stages of adult development who is best prepared to cope effectively with the life conditions we face. Epictetus, a Roman slave of Greek origin, who later came to be recognized as a great Stoic thinker, figured it out many centuries ago, and wise people have quoted his words in several settings since: "It is not what happens to you, but how you react to it that matters."If we are all spiritual beings with a human experience, then every workplace where people come together to perform is a spiritual one. What we have to strive for is to ensure that the degree of our workplace spirituality aligns with our personal spiritual needs. Mature leadership, high SQ leadership, is not about warm and fuzzy feelings. It is deep compassion manifesting in wise action. It is a profound personal integrity — an alignment with purpose and values. The high SQ leader understands the natural emergent processes at play and can work with them for the best outcomes, all while he/she stays focused on the big picture - remaining untriggered by old egoistic reactions. To do what is needed takes courage. But developing spiritual intelligence is a requirement if we want to access the highest stages of adult development and become truly mature leaders - leaders ready for the challenges we face. The world desperately needs a shift in consciousness in business, and every organization that takes steps in the direction of greater spirituality in the workplace is making a significant difference.

\section{References:}

[1]. "The Living Organization-spirituality in the work place " Prof. William A. Guillory.

[2]. "The $8^{\text {Th }}$ Habit"-Dr. Stephen R Covey.

[3]. Spirituality in the Workplace What It Is, Why It Matters, How to Make It Work for you” - Joan Marques, Satinder Dhiman, Richard King .

[4]. Thinking With Your Soul : Spiritual Intelligence and Why It Matters - Richard Wolman .

[5]. Ashmos, D.P. and Duchon, D. (2000). Spirituality at Work: A Conceptualization and Measure. Journal of Management Inquiry, 9(2): 134-145

[6]. A Spiritual Audit of Corporate America: Ten Years Later Spirituality and Attachment Theory, An Interim Report by Ian I. Mitroff, Ph.D. and Elizabeth A. Denton, Ph.D.

[7]. Organizational Consultant, New;

[8]. 'Built to last' by Jim Collins and Jerry I Porras.

[9]. Good to great by Jim Collins.

[10]. Great by choice by Jim Collins 